\title{
Location and Parameters of Power System Stabilizer for Small Perturbation of Tunisian Network
}

\author{
BEN SALAH Rim ${ }^{1}$, DJEBALI Meriam ${ }^{1}$, KAHOULI Omar ${ }^{1}$, BOUCHOUCHA Chokri ${ }^{2}$, HADJ ABDALLAH Hsan ${ }^{1}$ \\ ${ }^{1}$ Control \& Energies Management (CEM-Lab) \\ National Engineering School of Sfax, ENIS \\ ${ }^{2}$ Tunisian Company for Electricity and Gas (STEG)
}

\begin{abstract}
This paper proposes the static stability of Tunisian electrical network while facing small perturbation to maintain the security of the entire power system. In this context, after linearizing the power system, the concept of determining the placement of Power System Stabilizer is based on participation factor to find where it is going to be the most effective on a particular mode. Then, the Power System Stabilizer tuning is calculated by using the method of residue. Our objective is to improve the dynamic behavior of the electricity grid while facing various small disturbances.
\end{abstract}

Keywords - the static stability of Tunisian electrical network; Power System Stabilizer; Automatic Voltage Regulator; method residue.

\section{INTRODUCTION}

The purpose of a grid is to generate electrical power, and transport it to the load. A balance between the energy generated and the energy consumed must be maintained at all times. Besides, for a safe and reliable operation, the grid must be able to maintain stability while encountering several types of disturbances.

The electromechanical phenomena of small disturbances often occur with little damped oscillations of the system whose frequency range is between 0 to $2 \mathrm{~Hz}$ [1]. These oscillations can lead to destabilize an alternator, a part of the network or the whole network causing a loss of the synchronism and consequently the entire system would collapse.

The objective is to ensure a maximum damping of the inter-area modes as well as of the local modes, using Power System Stabilizers (PSS) which are habitually used for the damping of electromechanical local modes. The additional signal is injected into the input of the AVR

[2].
Conventionally, to adjust PSS tuning, the equations of nonlinear system model are linearized around the operating point. Furthermore, the problem of the PSSs adjustment is that the location must be optimal.

The problem of ensuring better locations for PSSs can be determined by the participation factors and their parameters can be calculated by the method of residues [1]. Then, the final decision for PSS placement was made by looking at the changes of the eigenvalues after installation of a PSS at the machine closely related to this mode.

This work presents the application of our approach in a multi-machine power system as the Tunisian grid [2]. The simulation is done by PSAT / MATLAB.

\section{POWER SYSTEM DYNAMIC MODEL}

\section{A. Machine Models}

The synchronous machine is the main source of electrical energy in power system. The multi-machine modeling adopted in this paper uses as dynamical variables for each generator the angular velocity $(\omega)$, the rotor angle $(\delta)$, the internal voltage of quadrature axis $q E_{-} q^{\wedge \prime}$ and the internal voltage of quadrature axis $d E d^{\wedge^{\prime}}[1,3,4]$.

Nonlinear dynamic equations of the each machine can be summarized as follows [5]:

$$
\dot{\delta}=\Omega_{\mathrm{b}}(\omega-1)
$$

$\dot{\omega}=\frac{\mathrm{T}_{\mathrm{m}}-\mathrm{T}_{\mathrm{E}}-\mathrm{D}(\omega-1)}{\mathrm{M}}$

$\dot{e}_{q}^{\prime}=\frac{-f_{s}\left(e_{q}^{\prime}\right)-\left(x_{d}-x_{d}^{\prime}\right) i_{d}+V_{f}^{*}}{T_{d 0}^{\prime}}$

$\dot{\mathrm{e}}_{\mathrm{d}}^{\prime}=\frac{-\left(\mathrm{e}_{\mathrm{d}}^{\prime}\right)+\left(\mathrm{x}_{\mathrm{q}}-\mathrm{x}_{\mathrm{q}}^{\prime}\right) \mathrm{i}_{\mathrm{q}}}{\mathrm{T}_{\mathrm{q} 0}^{\prime}}$ 
Where $\omega$ is electric speed [rd/s], Te is Electrical Torque [p.u], Tm is Mechanical Torque [p.u], $\mathrm{M}$ is Mechanical starting time [p.u/s], D is Damping coefficient [p.u/p.u], SE is equation of the magnetic circuit saturation, id is d-axis current [p.u], iq is q-axis

current [p.u], $x d$ is d-axis synchronous reactance [p.u], $x d^{\prime}$ is d-axis transient reactance [p.u], Td0' is daxis open circuit transient time constant [p.u], Tq0' is $\mathrm{q}$-axis open circuit transient time constant [p.u], $\mathrm{xq}$ is $q$ - axis synchronous reactance [p.u], $x q^{\prime}$ is $q$ - axis transient reactance [p.u] and $\mathrm{Vf}$ is field voltage [p.u].

\section{POWER SYSTEM CONTROLLER}

There are many types of power system regulators in order to enhance the stability, the margin of safety or the power transmitted by lines.

\section{Turbine governor and frequency controller}

The frequency controller acts on the servomotor to open and to close the control valves, also to change the speed of the generator. Thus, the role of the turbine is to drive the rotor of the synchronous generator speed. The $t g$ is the variable of the speed control.

In our case the speed controller TG is type II, it is described by the following equation [5]:

$\dot{t}_{g}=\frac{\frac{1}{R} *\left(1-\frac{T_{1}}{T_{2}}\right)\left(\omega_{\text {ref }}-\omega\right)-t_{g}}{T_{2}}$

Where wref is reference speed [p.u], T1 is Transient time constant of turbine governor [s], T2 is Time constant of turbine governor [s].

\section{Voltage regulator}

Automatic voltage regulator (AVR) is used to regulate the output voltage through controlling the excitation field. This regulator is used to vary the external voltage of the filter $\mathrm{Vm}$, the voltage of regulator $\mathrm{Vr} 1$, Vr2 and the field voltage Efd. The AVR is Type II.

It can be described as [5]:

$\dot{\mathrm{V}}_{\mathrm{m}}=\frac{\mathrm{V}_{\mathrm{g}}-\mathrm{V}_{\mathrm{m}}}{\mathrm{T}_{\mathrm{R}}}$

$$
\begin{aligned}
& \dot{V}_{\mathrm{r} 1}=\frac{\mathrm{K}_{\mathrm{A}}\left(\mathrm{V}_{\mathrm{ref}}-\mathrm{V}_{\mathrm{m}}-\mathrm{V}_{\mathrm{r} 2}-\frac{\mathrm{K}_{\mathrm{F}}}{\mathrm{T}_{\mathrm{F}}} \mathrm{E}_{\mathrm{fd}}\right)-\mathrm{V}_{\mathrm{r} 1}}{\mathrm{~T}_{\mathrm{A}}} \\
& \dot{\mathrm{V}}_{\mathrm{r} 2}=-\frac{\mathrm{V}_{\mathrm{r} 2}+\frac{\mathrm{K}_{\mathrm{F}}}{\mathrm{T}_{\mathrm{F}}} * \mathrm{E}_{\mathrm{fd}}}{\mathrm{T}_{\mathrm{F}}} \\
& \dot{\mathrm{E}}_{\mathrm{fd}}=\frac{-\left(\mathrm{E}_{\mathrm{fd}}\left(\mathrm{K}_{\mathrm{E}}+\mathrm{S}_{\mathrm{e}}\left(\mathrm{E}_{\mathrm{fd}}\right)-\mathrm{V}_{\mathrm{r} 1}\right)\right.}{\mathrm{T}_{\mathrm{E}}}
\end{aligned}
$$

Where Vref is reference voltage [p.u], $\mathrm{Vg}$ is terminal voltage of the generator [p.u], KA, TA are Amplifier gain and amplifier time constant respectively [p.u/p.u] and [s], KF, TF are stabilizer gain and stabilizer time constant [p.u/p.u] and [s], KE, TE are Parameter stabilizer respectively [p.u/p.u] and[s].

\section{Voltage regulator}

Power System Stabilizers (PSSs) are typically used for damping power system oscillations. The PSS output signal is the state variable vs, which modifies the reference voltage vref of the AVR.

They usually consist of four blocks: an amplifier block, "filter washout" block, a phase compensation block and a limiter block.

In our study, we used type II. PSSs are defined by this equation, as follows:

$\dot{\mathrm{V}}_{1}=-\frac{\left(\mathrm{K}_{\omega} * \mathrm{~V}_{\mathrm{SI}}+\mathrm{V}_{1}\right)}{\mathrm{T}_{\omega}}$

$\dot{\mathrm{V}}_{2}=\frac{\left(1-\frac{\mathrm{T}_{1}}{\mathrm{~T}_{2}}\right) *\left(\mathrm{~K}_{\omega} * \mathrm{~V}_{\mathrm{SI}}+\mathrm{V}_{1}\right)-\mathrm{V}_{2}}{\mathrm{~T}_{2}}$

$\dot{\mathrm{V}}_{3}=\frac{\left(1-\frac{\mathrm{T}_{3}}{\mathrm{~T}_{4}}\right) *\left(\mathrm{~V}_{2}+\left(\frac{\mathrm{T}_{1}}{\mathrm{~T}_{2}} *\left(\mathrm{~K}_{\omega} * \mathrm{~V}_{\mathrm{SI}}+\mathrm{V}_{1}\right)\right)-\mathrm{V}_{3}\right)}{\mathrm{T}_{4}}$

$\dot{\mathrm{V}}_{\mathrm{pss}}=\frac{\mathrm{V}_{3}+\frac{\mathrm{T}_{3}}{\mathrm{~T}_{4}} *\left(\mathrm{~V}_{2}+\frac{\mathrm{T}_{1}}{\mathrm{~T}_{2}} *\left(\mathrm{~K}_{\omega} * \mathrm{~V}_{\mathrm{SI}}+\mathrm{V}_{1}\right)\right)-\mathrm{V}_{\mathrm{pss}}}{\mathrm{T}_{\epsilon}}$

Where Vpss is voltage (PSS) [p.u], Tw is time constant filter [s], Kw is stabilizer gain [p.u], T1 is First stabilizer time constant [s], T2 is Second stabilizer time constant [s], T3 is Third stabilizer time constant 
[s], T4 is Fourth stabilizer time constant [s].

"Fig. 1" presents the AVR and the PSS

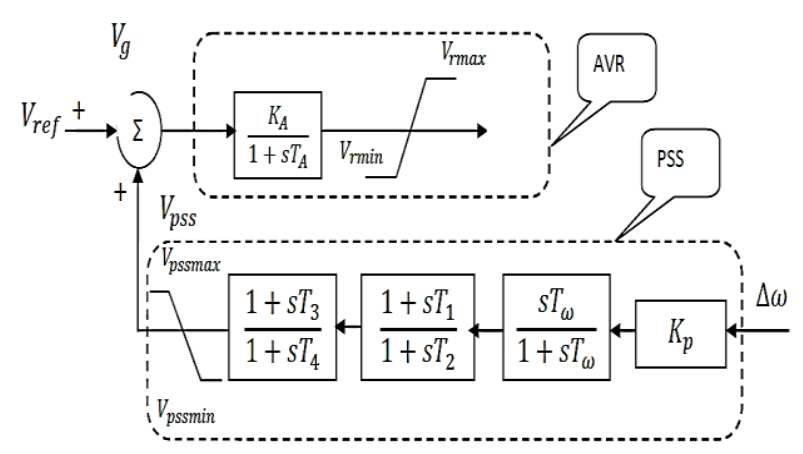

Fig .1. combinaison of AVR and PSS

\section{POWER SYSTEM CONTROLLER}

The general dynamic equations of the relevant system can be expressed by a set of nonlinear differential equations in the following form:

$$
\left\{\begin{array}{l}
\dot{x}=\mathrm{f}(\mathrm{x}, \mathrm{u}) \\
y=\mathrm{g}(\mathrm{x}, \mathrm{u})
\end{array}\right.
$$

Let $x 0$ be the initial state vector, and $u 0$ the input vector corresponding to the equilibrium point.

The linearized system of the equation(14), which includes a synchronous generator connected over transmission lines to an AC network, is represented as the following state-space model $[6,7]$ :

$\left\{\begin{array}{l}\Delta \dot{x}=A \Delta x+B \Delta u \\ \Delta y=C \Delta x+D \Delta u\end{array}\right.$

Where $A$ is the power system state matrix of size $\left(n^{*} n\right), B$ is the input matrix of size $\left(n^{*} r\right), C$ is the output matrix of size $\left(m^{*} n\right), D$ is the feed forward matrix of size $\left(m{ }^{*} r\right)$.

The variables described above and the linearized equations define the linear system are:

$$
\left\{\begin{array}{c}
\Delta X=\left[\Delta \delta_{1} \Delta \omega_{1} \Delta E_{q 1}^{\prime} \Delta E_{d 1}^{\prime} \ldots \Delta \delta_{n} \Delta \omega_{n} \Delta E_{q n}^{\prime} \Delta E_{d n}^{\prime} \Delta V_{m 1}\right. \\
\left.\Delta V_{r 11} \Delta V_{r 21} \ldots \Delta V_{m n} \Delta V_{r 1 n} \Delta V_{r 2 n} \Delta t g_{1} \ldots \Delta t g_{n}\right]^{T} \\
\Delta \mathrm{U}=\left[\Delta V_{\text {ref1 } 1 \ldots \ldots . . .} \ldots V_{\text {refn }}\right]^{\mathrm{T}} \\
\Delta \mathrm{U}=\left[\Delta \mathrm{V}_{\text {ref1 } \left.1 \ldots \ldots . . \Delta V_{\text {refn }}\right]^{\mathrm{T}}}\right.
\end{array}\right.
$$

Where $\Delta \mathrm{X}$ is the state vector of dimension $\mathrm{n}, \Delta \mathrm{Y}$ is the output vector of dimension $\mathrm{m}$ and $\Delta \mathrm{U}$ is the input vector of dimension $r$.

\section{A. Eigenvalues}

The analysis of eigenvalues is a very effective tool to study the properties of the dynamic systems. The eigenvalues $(\lambda)$ of the state matrix are given by the solutions of the characteristic equation of the state matrix $A$. It is defined by $[1,9,10,11]$ :

$$
\operatorname{det}(\lambda \mathrm{I}-\mathrm{A})=0
$$

Each eigenvalues has a real part of complex eigenvalues which provides the damping coefficient, and an imaginary part which gives the oscillation frequency. These are defined by the following expression.

$$
\lambda=\sigma \pm j \omega
$$

The system will be stable if all the eigenvalues have a negative real part in the complex plane.

The following relations give the frequency of oscillation:

$$
f=\frac{\omega}{2 \pi}
$$

The damping factor sets the decreasing of the oscillation amplitude. It is given by :

$$
\xi=\frac{-\sigma}{\sqrt{\sigma^{2}+\omega^{2}}}
$$

\section{B. Eigenvectors}

The linear model of the power system can be represented and described by equation (14).

The eigenvectors is calculated. The right and left eigenvector related to the state matrix of the system by the following equations $[12,13]$ :

$$
\begin{aligned}
& A \varphi_{i}=\lambda_{i} \varphi_{i} \\
& \psi_{\mathrm{i}} \mathrm{A}=\lambda_{\mathrm{i}} \psi_{\mathrm{i}}
\end{aligned}
$$

$\lambda \_i$ : the ith eigenvalues $; \varphi_{-}$i: the right eigenvector 
For a state matrix of dimension $\mathrm{n} \times \mathrm{n}$, the specific vector is a right column vector of dimension $n \times 1$, while the left eigenvector is a row vector of dimension $\mathrm{n} \times 1$.

The two vectors are defined as follows:

$$
\varphi_{\mathrm{i}}=\left[\begin{array}{c}
\varphi_{1 \mathrm{i}} \\
\varphi_{2 \mathrm{i}} \\
\cdot \\
\cdot \\
\cdot \\
\varphi_{\mathrm{ni}}
\end{array}\right] \quad, \quad \psi_{\mathrm{i}}=\left[\begin{array}{lll}
\Psi_{1 \mathrm{i}} & \ldots & \psi_{\mathrm{ni}}
\end{array}\right]
$$

The set of right eigenvectors of the system to form the right modal matrix is given as follows:

$$
\Phi=\left[\begin{array}{lll}
\phi_{1} & \ldots & \phi_{\mathrm{n}}
\end{array}\right]
$$

The left modal matrix is formed by the left vectors:

$$
\Psi=\left[\begin{array}{lll}
\Psi_{1}^{\mathrm{T}} & \ldots & \psi_{\mathrm{n}}^{\mathrm{T}}
\end{array}\right]^{\mathrm{T}}
$$

The right vector $\varphi \mathrm{i}$ shows the relative influence of each variable in an excited state. The eigenvector left $\psi i$ mode, it determines the set of state variables involved regarding the composition of ith mode.

\section{Participation Factor}

The participation factor, which combines both the right and left eigenvectors, is defined by a matrix of participation in the following form [14]:

$\mathrm{P}=\left[\begin{array}{llllll}\mathrm{p}_{1} & \mathrm{p}_{2} & \cdots & \mathrm{p}_{\mathrm{i}} & \cdots & \mathrm{p}_{\mathrm{n}}\end{array}\right]$

Which

$$
\mathrm{P}_{\mathrm{i}}=\left[\begin{array}{c}
\mathrm{p}_{1 \mathrm{i}} \\
\mathrm{p}_{2 \mathrm{i}} \\
\vdots \\
\mathrm{p}_{\mathrm{ni}}
\end{array}\right]=\left[\begin{array}{c}
\phi_{1 \mathrm{i}} \psi_{1 \mathrm{i}} \\
\phi_{2 \mathrm{i}} \psi_{2 \mathrm{i}} \\
\vdots \\
\phi_{n \mathrm{i}} \psi_{\mathrm{ni}}
\end{array}\right]
$$

During the study of the stability at small disturbances, the participation factors allow the influence of a source of damping applied to a generator.

In the participation matrix $\mathrm{P}$, as shown in equation
(25), the jth column shows how the user participates with respect to the evolution of the state variables of the system while the line ith shows how the different modes involved relatively the evolution of the ith state variable [15].

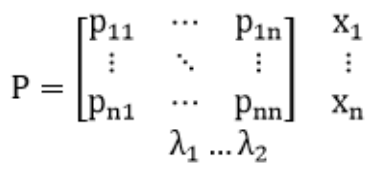

The participation factors allow to us the identification of variables participants at specific oscillatory mode.

\section{Residue}

The residues give an idea about the influence of the input stabilization or its optimal location in a multimachine power system. The transfer function affects only the behavior of inputs-outputs [1, 3].

Considering the following system :

$\left\{\begin{array}{c}\Delta \dot{x}=A \Delta x+B \Delta u \\ \Delta y=C \Delta x\end{array}\right.$

The transfer function is as follows:

$G(s)=\frac{\Delta y(s)}{\Delta u(s)}=\mathrm{C}(s I-A)^{-1} \mathrm{~B}$

s: Laplace operator.

The function $G$ (s) can be composed by simple elements as follows:

$G(s)=\frac{R_{1}}{s-p_{1}}+\frac{R_{2}}{s-p}+\cdots+\frac{R_{n}}{s-p_{n}}=\sum_{i=1}^{n} \frac{R_{i}}{s-p_{i}}=\sum_{i=1}^{n} \frac{R_{i}}{s-\lambda_{i}}$

Where $\mathrm{Ri}$ is the residues of $\mathrm{G}(\mathrm{s})$ given by:

$\mathrm{R}_{\mathrm{i}}=\mathrm{C} \phi_{\mathrm{i}} \psi_{\mathrm{i}} \mathrm{B}$

\section{CONTROL POWER SYSTEM}

\section{A. Optimal Placement of Power System Controller}

When installing such as a controller in multi-machine networks, the first conventional step is to find its optimum location within the network.

To damp the local modes, the choice of location is still easy because the number of generators implicated mostly in local oscillations is very small. 
On the other hand, for global modes, a great number of generators are generally associated with oscillations. That complicates the choice of the location of the PSS. In addition, a bad location of PSS can result in amplification of the oscillations, or contribute to the loss of stability of the system.

When a PSS is added in the system, it will affect all the electromechanical oscillation modes. Thus, the interactions between PSS must be considered when several PSSs are used [1].

All PSS should be adjusted to provide sufficient damping of all electromechanical modes because the damping of each mode has a cumulative effect on the contribution of each PSS.

Moreover, adjustment of PSS must be robust: PSS must be efficient not only during the change of the operating conditions but also when changing the network topology.

\section{B. Design of PSS}

To improve the stability of the system, the power system stabilizers that are simple and easy to install, practical, effective and cheap are often the most common stabilizers that are used to damp these oscillations as much as possible and also to increase the damping of oscillatory modes.

These parameters of PSS are adjusted sequentially and separately by method of residues [16].

The latter method of sequential setting usually gives satisfactory results for the damping of the oscillations. In this method, PSS are resolved in a phased manner [16]:

- First, the residual of transfer function at open loop system is calculated. Then a PSS is added and used the information of these residues.

- Next, a second PSS is introduced and set based on information of the residues with the first PSS.

- This process continues until the system reaches satisfactory stability characteristics.

The most method used for the selection of machines, which must be equipped with PSS, is the method of Participation Factors $[1,10,14,17,18,19]$. The transfer function of the PSS for a system with an input / output is:

$\mathrm{H}(\mathrm{s})=\mathrm{K}_{\mathrm{p}} \frac{\mathrm{sT}_{\mathrm{w}}}{1+\mathrm{sT}_{\mathrm{w}}} \cdot\left[\frac{1+\mathrm{T}_{1}}{1+\mathrm{T}_{2}}\right]^{\mathrm{p}}=\mathrm{K}_{\mathrm{p}} \mathrm{H}_{\mathrm{f}}(\mathrm{s})$

Where T_w: The constant of the high pass filter, $T \_1, T 22$ : The time constants of the controller, $p$ : number of blocks lead / lag phase, $K \_p: g a i n$

"Fig. 2" presents the moving of eigenvalue to another value.

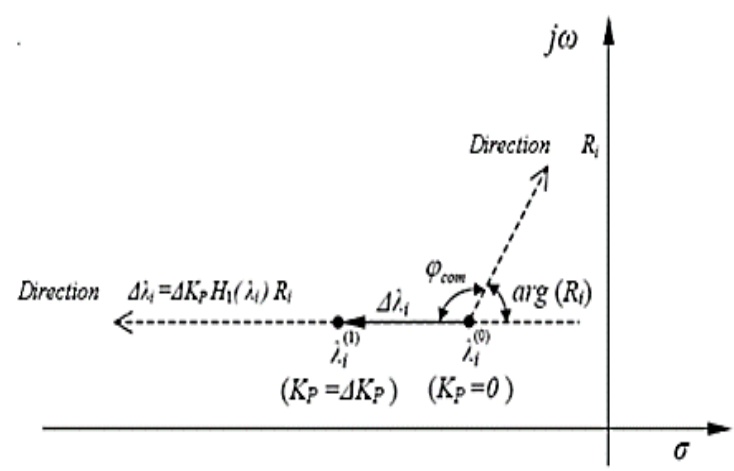

Fig. 2. Moving of eigenvalue

Moving these eigenvalues may be calculated by the following equation [20]:

$\Delta \lambda_{i}=\left|\lambda_{i 1}-\lambda_{i 0}\right|=R_{i} \mathrm{H}\left(\lambda_{i}\right)$

Where are calculated in equation (31)

The methodology of sizing residue is divided into three stages

- $\quad$ Sizing the filter "washout" We usually take Tw = 5s [1].

- Sizing Block lead / lag phase: the total phase shift required $\varphi_{-}$com is calculated from the residue of the critical mode. The phase angle required to direct the direction of the residue $R_{-} i$ so that the eigenvalue $\lambda_{-}(i)$ moves parallel to the real axis can be calculated by the following equation:

$$
\varphi_{\text {com }}=180^{\circ}-\arg \left(R_{i}\right)
$$

The time constants $\mathrm{T} 1$ and $\mathrm{T} 2$ can be determined by:

$$
\mathrm{T}_{2}=\frac{1}{\omega_{\mathrm{i}} \sqrt{\alpha}}
$$




$$
\mathrm{T}_{1}=\alpha \cdot \mathrm{T}_{2}
$$

With : $\omega \_i$ : est la fréquence du mode $\lambda \_i$ en $\mathrm{rad} / \mathrm{sec}$

$$
\alpha=\frac{1-\sin \frac{\varphi_{\text {com }}}{p}}{1+\sin \frac{\varphi_{\text {com }}}{p}}
$$

- With a good lead-lag compensation, controller efficiency is related to the gain 《K K\_p [16]. Consequently, when we have a change of $K \_p$, all modes of oscillation will be influenced.

To calculate the gain \ $\mathrm{K} \rrbracket \_p$, here is the transfer function following PSS:

$$
\mathrm{H}(\mathrm{s})=\mathrm{K}_{\mathrm{p}} \mathrm{H}_{\mathrm{f}}(\mathrm{s})
$$

Based on the equations (33) and (38), the gain value $\mathrm{K} \_\mathrm{p}$ is given by the following expression:

$$
K_{p}=\left|\frac{\lambda_{i 1}-\lambda_{i 0}}{R_{i} H_{f}\left(\lambda_{i}\right)}\right|
$$

The output signal $y(s)$ may be selected based on the maximum value of the residue data selected by the outputs [19].

In fact, not all the generators associated with electrical networks need to be equipped with PSS since they do not participate in all of the most dominant electromechanical modes.

Therefore, the first step is to find the optimal locations of PSS needed and determine their number using important information provided by the factor of interests whose goal is to achieve better damping compared to given criteria.

\section{RESULTS AND SIMULATIONS}

The local modes are the most recurrent modes encountered in power systems. They are associated with oscillations between a generator (and a group of generators) of a power plant and the rest of the system.

The local modes and inter modes, with frequencies of these oscillations are typically in the range of 0.2 to 2 $\mathrm{Hz}$, are studied. This application was processed on the Tunisian network system generation and transmission of electric power STEG.

It consists of a network for transferring electrical energy production centers to consumption centers which are geographically often far away from each other.

Tunisian network (2012 version) consists of 3 wind farms, 172 lines, 83 transformers, 33 generators, 75 knots consumers.

A. Application on the Tunisian network

Initially, before the use of PSS, yet we had to ensure adequate damping of the oscillations, the method of residues will allow us to provide better localization of PSS and better coordination of their parameters [2].

\section{Location of PSS}

The electromechanical generator participation factor is the first method used in this study; it allows us to determine the participation of a machine in each mode. Thus, for a desired mode to be damped, the machine that participates the most is the machine where the PSS should be installed.

In our case, 14 generators mainly participate in 11 modes.Next the frequency of each mode and the associated generator, the type of each mode is determined. Then 11 modes are selected:

- 3 modes of interregional -type.

- 8 modes of local type.

The results are given in "Tab.1":

Table 1. Participants Generators

\begin{tabular}{|c|c|c|c|c|}
\hline $\begin{array}{c}\mathbf{N}^{\circ} \\
\text { Mode }\end{array}$ & Eigenvalue & $\begin{array}{c}\text { Fre- } \\
\text { quency }\end{array}$ & $\begin{array}{c}\text { Generators } \\
\text { participants }\end{array}$ & $\begin{array}{c}\text { The mode } \\
\text { type }\end{array}$ \\
\hline $\mathbf{1}$ & $-0,99146 \pm 10,3388 \mathrm{i}$ & 1.653 & $\mathrm{G} 1$ & Local \\
\hline $\mathbf{2}$ & $-0,66359 \pm 11,8818 \mathrm{i}$ & 1.894 & $\mathrm{G} 3, \mathrm{G} 4$ & Local \\
\hline $\mathbf{3}$ & $-0.92013 \pm 7.1822 \mathrm{i}$ & 1.1524 & $\mathrm{G} 10, \mathrm{G} 18$ & Local \\
\hline $\mathbf{4}$ & $-0.43648 \pm 8.1696 \mathrm{i}$ & 1.3021 & $\mathrm{G} 11$ & Local \\
\hline $\mathbf{5}$ & $-0.77795 \pm 11.3363 \mathrm{i}$ & 1.8085 & $\mathrm{G} 13$ & Local \\
\hline $\mathbf{6}$ & $-0.51007 \pm 5.6611 \mathrm{i}$ & 0.90463 & $\mathrm{G} 15, \mathrm{G} 23$ & Interrégional \\
\hline $\mathbf{7}$ & $-0.49009 \pm 5.8498 \mathrm{i}$ & 0.93429 & $\mathrm{G} 16$ & Interrégional \\
\hline $\mathbf{8}$ & $-0.44439 \pm 11.2483 \mathrm{i}$ & 1.7916 & $\mathrm{G} 19$ & Local \\
\hline $\mathbf{9}$ & $-0.89544 \pm 7.2212 \mathrm{i}$ & 1.1581 & $\mathrm{G} 22$ & Local \\
\hline $\mathbf{1 0}$ & $-0.73736 \pm 11.9208 \mathrm{i}$ & 1.9009 & $\mathrm{G} 27$ & Local \\
\hline $\mathbf{1 1}$ & $-0.33778 \pm 5.2691 \mathrm{i}$ & 0.84032 & $\mathrm{G} 33$ & Interrégional \\
\hline
\end{tabular}


Factor analysis of participation shows the influence of each generator in that mode. If the participation of a generator is relatively small, the placement of a PSS on this generator provides little improvement.

"Fig.3" and "Fig.4" show the participation factors (PF) associated to the angle and the speed variations of each generator for the 11 electromechanical modes.
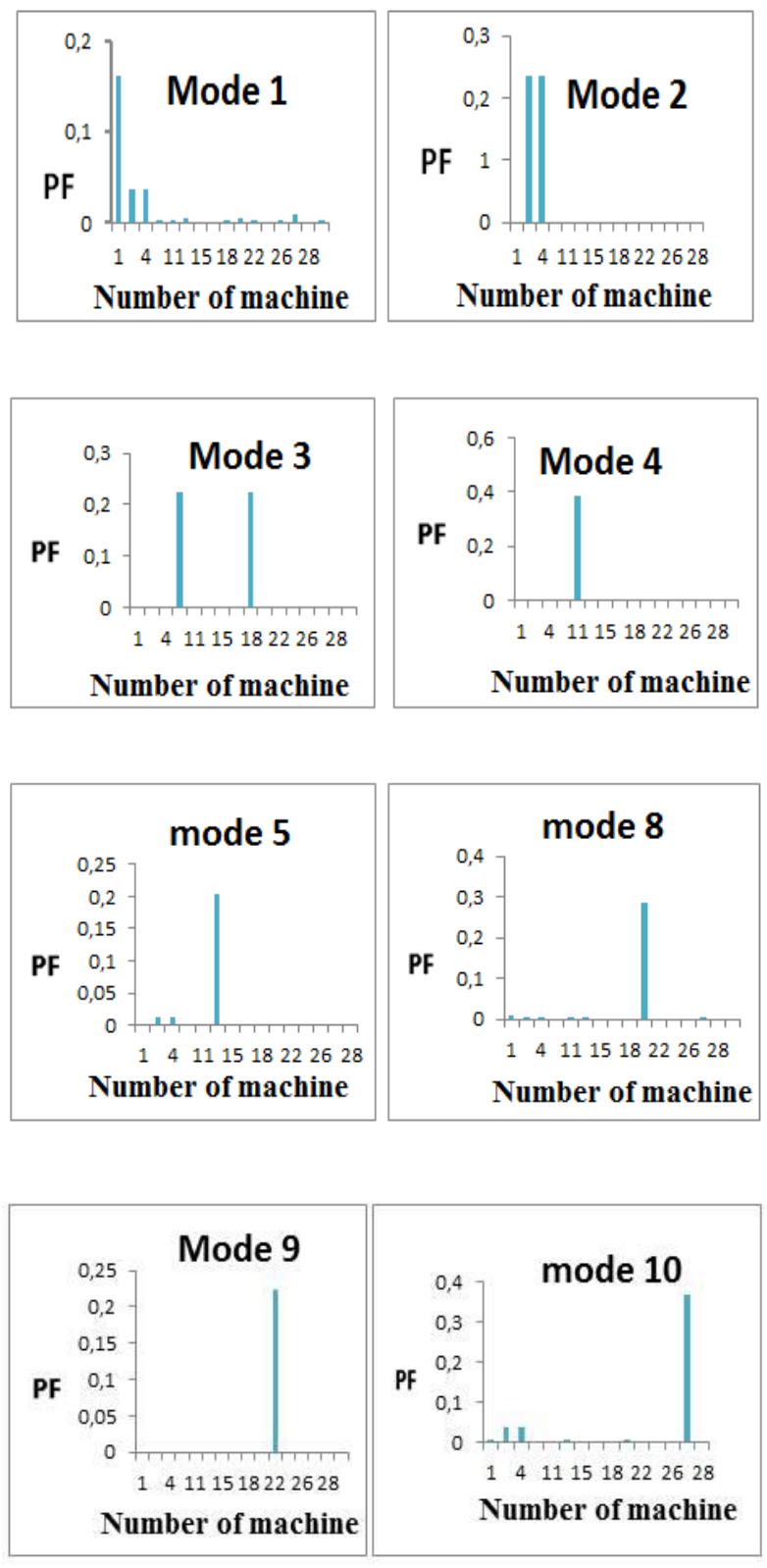

Fig. 3.The participation factors (PF) of local modes
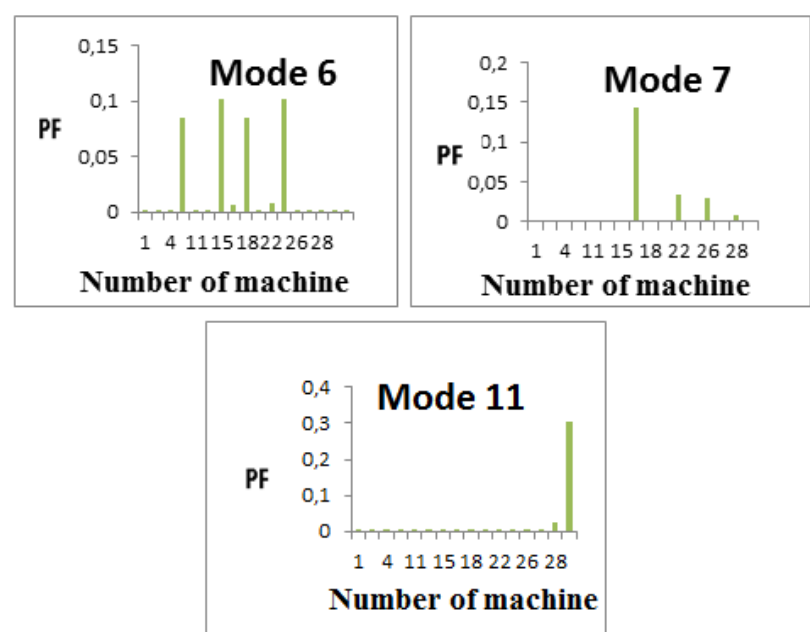

Fig. 4. The participation factors (PF) interregional modes

\section{Setting the parameters of the PSS}

To restore system stability and improve its overall damping, the PSS is added to the desired generators. In the remainder of this section, the residue method is used to determine the parameters of the PSSs. These are summarized in "Tab.2":

Table 2. Parameters of PSS by the residue method

\begin{tabular}{|c|c|c|c|c|}
\hline PSS & $\mathbf{N}^{\circ} \mathbf{G}$ & KPSS & $\mathbf{T}_{\mathbf{1}}=\mathbf{T}_{\mathbf{3}}$ & $\mathbf{T}_{\mathbf{2}} \mathbf{T}_{\mathbf{4}}$ \\
\hline 1 & 1 & 0.0099 & 0.7970 & 0.0117 \\
\hline 2 & 3 & 0.0538 & 0.3196 & 0.0222 \\
\hline 3 & 4 & 0.6756 & 0.1053 & 0.0673 \\
\hline 4 & 10 & 0.0147 & 2.9297 & 0.0066 \\
\hline 5 & 11 & 1.4230 & 0.1922 & 0.0780 \\
\hline 6 & 13 & 0.0022 & 0.9039 & 0.0086 \\
\hline 7 & 15 & 3.3088 & 0.1889 & 0.1652 \\
\hline 8 & 16 & 0.5092 & 0.4494 & 0.0650 \\
\hline 9 & 18 & 0.0147 & 2.9324 & 0.0066 \\
\hline 10 & 19 & 0.0396 & 0.5533 & 0.0143 \\
\hline 11 & 22 & 8.2752 & 0.1618 & 0.1185 \\
\hline 12 & 23 & 3.3062 & 0.1888 & 0.1653 \\
\hline 13 & 27 & 0.4044 & 0.1744 & 0.0403 \\
\hline 14 & 33 & 0.3312 & 0.9549 & 0.0377 \\
\hline
\end{tabular}

1. Analysis of the eigenvalues

To demonstrate the effectiveness of the proposed approach, two cases are considered:

- Without PSS

- With PSS 
The eigenvalues electromechanical modes for the both cases, their improvement and the improvements of the damping are given in "Tab.3":

Table 3. Improving eigenvalue and damping

\begin{tabular}{|c|c|c|c|c|}
\hline $\begin{array}{c}\mathbf{N}^{\circ} \\
\mathbf{G}\end{array}$ & $\begin{array}{c}\text { Eigenvalue } \\
\text { without PSS }\end{array}$ & $\begin{array}{c}\text { Eigenvalue with } \\
\text { PSS }\end{array}$ & $\begin{array}{c}\text { improvement } \\
\text { of } \\
\text { Eigenvalue }\end{array}$ & $\begin{array}{c}\text { Imrovement } \\
\text { Of } \\
\text { damping }\end{array}$ \\
\hline 1 & $-0,99146 \pm 10,3388 \mathrm{i}$ & $-1,0142 \pm 10,3394$ & $2 \%$ & $17 \%$ \\
\hline 3 & $-0,66359 \pm 11,8818 \mathrm{i}$ & $-0,74261 \pm 11,9396 \mathrm{i}$ & $8 \%$ & $2 \%$ \\
\hline 4 & $-0,66359 \pm 11,8818 \mathrm{i}$ & $-0.71031 \pm 11.8841 \mathrm{i}$ & $5 \%$ & $2 \%$ \\
\hline 10 & $-0.92013 \pm 7.1822 \mathrm{i}$ & $-0.92906 \pm 7.2014 \mathrm{i}$ & $1 \%$ & $1 \%$ \\
\hline 11 & $-0.43648 \pm 8.1696 \mathrm{i}$ & $-0.44521 \pm 8.0851 \mathrm{i}$ & $1 \%$ & $1 \%$ \\
\hline 13 & $-0.77795 \pm 11.3363 \mathrm{i}$ & $-0.8044 \pm 11.4987 \mathrm{i}$ & $3 \%$ & $2 \%$ \\
\hline 15 & $-0.51007 \pm 5.6611 \mathrm{i}$ & $-0.5361 \pm 5.6987 \mathrm{i}$ & $3 \%$ & $3 \%$ \\
\hline 16 & $-0.49009 \pm 5.8498 \mathrm{i}$ & $-0.49903 \pm 5.85 \mathrm{i}$ & $1 \%$ & $1 \%$ \\
\hline 18 & $-0.92013 \pm 7.1822 \mathrm{i}$ & $-0.92906 \pm 7.2014 \mathrm{i}$ & $1 \%$ & $1 \%$ \\
\hline 19 & $-0.44439 \pm 11.2483 \mathrm{i}$ & $-0.55527 \pm 11.2923 \mathrm{i}$ & $11 \%$ & $2 \%$ \\
\hline 22 & $-0.89544 \pm 7.2212 \mathrm{i}$ & $-0.90357 \pm 7.228 \mathrm{i}$ & $1 \%$ & $1 \%$ \\
\hline 23 & $-0.51007 \pm 5.6611 \mathrm{i}$ & $-0.53523 \pm 5.8241 \mathrm{i}$ & $3 \%$ & $3 \%$ \\
\hline 27 & $-0.73736 \pm 11.9208 \mathrm{i}$ & $-0.74291 \pm 11.9542 \mathrm{i}$ & $1 \%$ & $1 \%$ \\
\hline 33 & $-0.33778 \pm 5.2691 \mathrm{i}$ & $-0.48524 \pm 5.1309 \mathrm{i}$ & $15 \%$ & $1 \%$ \\
\hline
\end{tabular}

Based on the analysis of the eigenvalues of the system, the electromechanical modes (local and inter) are improved.

To see this improvement, here is the breakdown of some eigenvalues in the complex plane which are given respectively in" Fig.5".

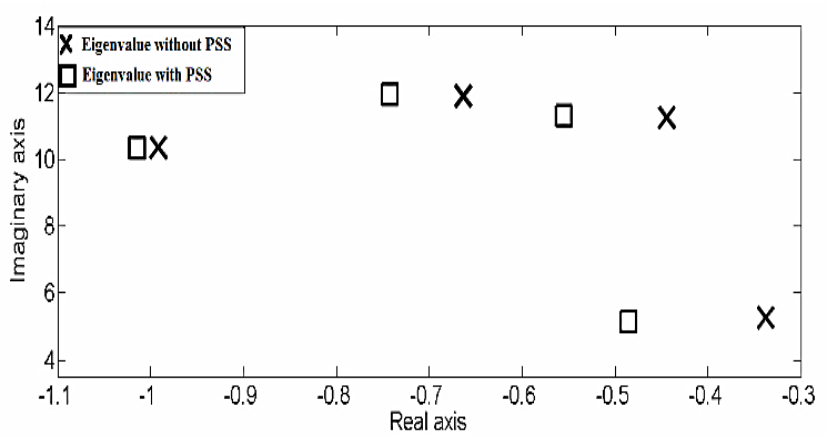

Fig. 5. Distribution of some eigenvalues in the complex space

As a second step, the performance and robustness of the setting of these regulators are evaluated. To do this, time domain simulations of the system in the presence of severe disturbance is done: load variation for both cases "Fig.6" and "Fig.7":

- Before location of PSS.
- After location of PSS.

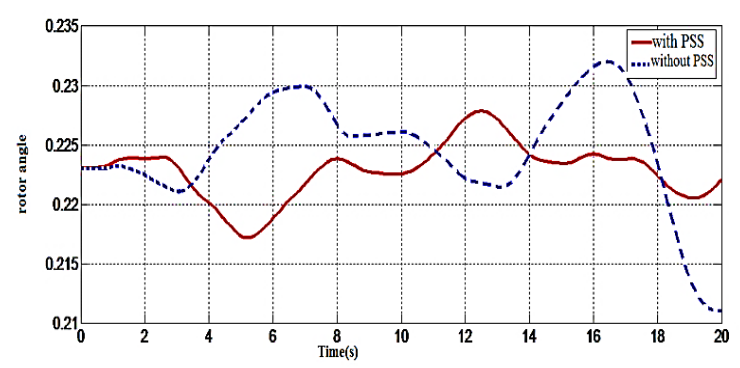

Fig. 6. Variation of the rotor angle for the machine 11

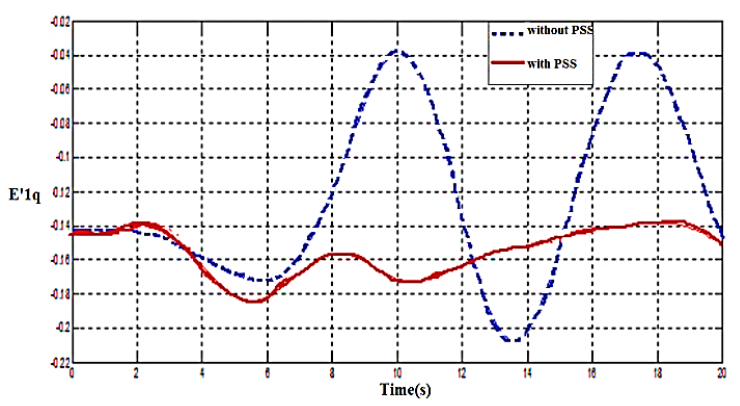

Fig. 7. Variation of the transient voltage 【E'1】_q for the machine 11

The amplitude of oscillations is reduced in the presence of PSS and the system becomes more

stable in less time if compared to the network without PSS.Finally and after a simulation of the selected Tunisian improved network software. "Fig.8" showing the location of the eigenvalues of the system in the complex plane.

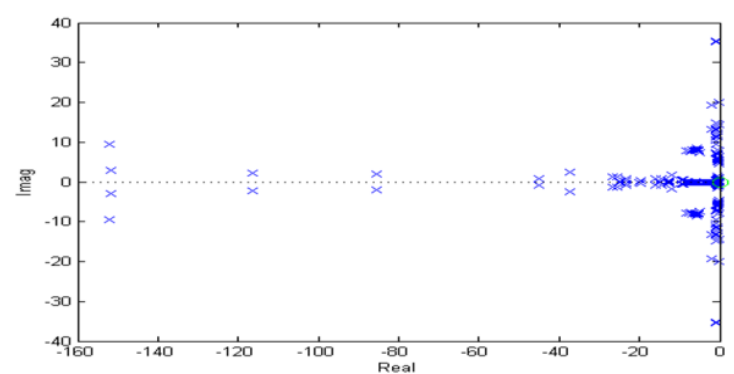

Fig. 8. Position of the eigenvalues of the Tunisian system

The most of the eigenvalues has a negative real part. The system is then stable.

\section{v. CONCLUSION}

Power systems continue to grow. The extension of networks interconnected makes them highly sensitive to interregional oscillations. These oscillations can severely restrict the transport of electrical energy. 
Under these new conditions, operators of electrical networks are often required to operate the systems to the limits of stability. Therefore, improving the stability to small perturbations represents an objective. In this work, the problem of the dynamics of a network of multi Machine stability distribution was handled. The nonlinear model of a network of electric power multi machine was developed. The nonlinear model was linearized to derive the model Philips-Heffron.Using the method of residues based on the eigenvalues of the system; providing, passing by the conventional method of participation factors, not just a calculation of parameters stabilizers PSSs, but also a better location and an interesting reduction in their number. In this study, the PSSs satisfy both the damping of inter modes also the damping of local modes As perspective, the utility of using the method of residues on another network that combines two different regions of the world such as interconnection Tunisia-Libya will be validated.

\section{REFERENCES}

[1] ALKHATIB, H. (2008) Etude de la stabilité aux petites perturbations dans les grands réseaux électriques : optimisation de la régulation par une méthode méta heuristique. Thèse de doctorat, Université Paul Cézanne d'AixMarseille,

[2] Rim, B. S. Mariam, D. (2014) Etude De La Stabilité Statique Du Réseau Tunisien Et De L'interconnexion Tunisie-Lybie. projet de fin d'étude, ENIS,

[3] Kalifullah A. Palanis., H. (2014) Optimal Tuning of PI Power System Stabilizer For Multi Machine Power System Using Harmony Search Algorithm. JATIT,

[4] Asrar Ur Rahman, M. Sabah ul Islam M, and Abdul Hafeez Ansari M. (2014) Enhancing Power System Oscillation Damping Using Coordinated PSS and SVC Controller. IJESI,

[5] Milano, F. (2006) Power System Analysis Toolbox Documentation for PSAT» version 2.0.0

[6] Wang,Sh. K, Ji-Pyng Chiou,Ch. W. L. (2008) Parameters Tuning Of Power System Stabilizers Using Improved Ant Direction Hybrid Differential Evolution . ELSEVIER,

[7] Ali, E. S., Abd-Elazim, S. M. (2013) Optimal Power System Stabilizers Design For Multimachine Power System Using Hybrid BFOA-PSO Approach . dep of wseas transactions on power systems,

[8] Usman, J. Mustafa,M. W.and Aliyu,G. (2012) Design Of AVR And PSS For Power System Stability Based On Iteration Particle Swarm Optimization.

[9] Zitouni M. F. (2010) Amélioration de la Stabilité Transitoire des Réseaux Electriques par l'utilisation des Systèmes FACTS.

[10] Febres C.A.T., Araujo P.B. Damping of LowFrequency Oscillations by Supplementary Control of Power System Stabilizers .

[11] Sumina .D, Bulic, Miskovic, N.M. (2011) Parameter Tuning Of Power System Stabilizer Using Eigenvalue Sensitivity », ELSEVIER,

[12] Kartubi, L. (2006) Optimisation de la Synthèse des FACTS par les Algorithmes Génétiques et les Essaims Particulaires pour le contrôle des Réseaux Electriques., p43

[13] Bragason R. F. (2008) Damping In The Icelandic Power System Small Signal Stability Analysis And Solutions. Dept. of Industrial Electrical Engineering and Automation Lund University,

[14] Duc, H.N.( 2011) Amélioration De L'amortissement Des Oscillations De Puissance Du Réseau Electrique Les Dispositifs Facts Et Les Mesures A Distance.

[15] Custem T.V., (2002) Systèmes Electriques de Puissance II. Cours ELEC 047, Département d'Electricité, Electronique et Informatique : Institut Montefiore, Université de Liège,.

[16] Yee S.K. and Milanovic J.V (June. 2004) Comparison Of The Optimization And Linear Sequential Method For Tuning Of Multiple PSSs. IEEE Power Engineering Society, General Meeting Denver, CO,.

[17] Mekki K. (2002) Mesures Synchronisées par GPS pour une Meilleure Stabilité des Réseaux.

[18] Zea A. A. (2013) Power System Stabilizers for the Synchronous: Generator Tuning and Performance Evaluation.

[19] Sebaa M. K. (2008) Commande intelligente pour l'amélioration de la stabilité dynamique des réseaux d'énergie électrique.

[20] Ammari S. (2000) Interaction des dispositifs Facts avec les charges dynamiques dans les réseaux de transport et d'interconnexion 